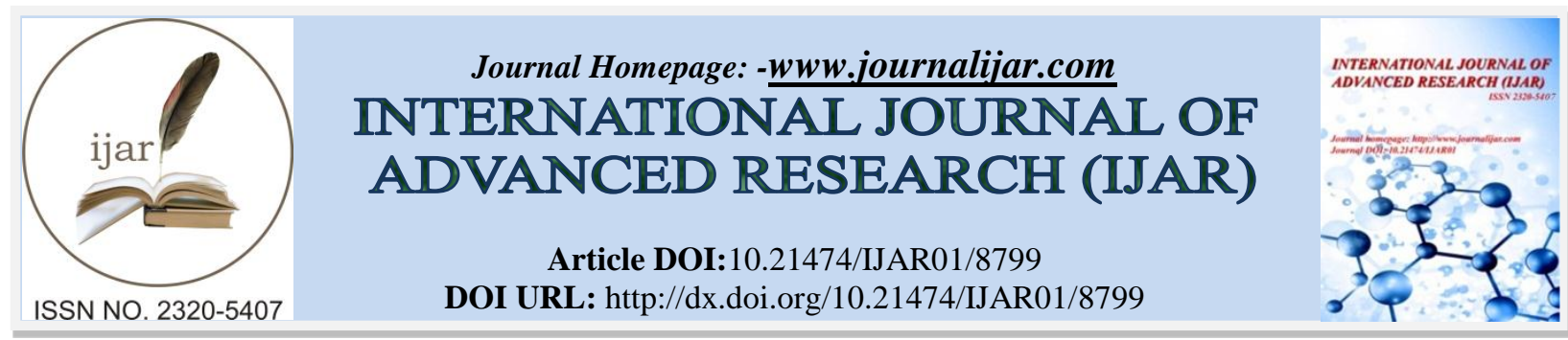

RESEARCH ARTICLE

\title{
EFFECT OF INJECTION TIMING AND NOZZLE HOLE GEOMETRY ON COMPRESSION IGNITION ENGINE FUELLED WITH THEVETIA PERUVIANA BIODIESEL.
}

\section{A. J. Deokar ${ }^{1}$ and Dr. G. R. Selokar ${ }^{2}$.}

1. Research Student, Sri Satya Sai University of Technology and Medical Sciences, Sehore, Madhya Pradesh 466001.

2. Research Guide, Sri Satya Sai University of Technology and Medical Sciences, Sehore, Madhya Pradesh 466001.

\section{Manuscript Info}

(..........................

Manuscript History

Received: 03 February 2019

Final Accepted: 05 March 2019

Published: April 2019

Key words:-

Blends, Compression Ignition, Emission,

Nozzle, Timing, Performance.

\begin{abstract}
In the present study an experimental work had been carried out to analyze the performance and emission characteristics of various blends of thevetia peruviana biodiesel by varying injection timings and nozzle hole geometry. The engine tests are conducted on Kirloskar, 4-stroke, single cylinder, $1500 \mathrm{rpm}$, water cooled, direct injection, diesel engine with Eddy Current Dynamometer with standard injection pressure 230 bar and injection timing $23^{\circ} \mathrm{BTDC}$ was maintained constant throughout the experiment. Three different injection timings such as $20^{\circ} \mathrm{BTDC}$, $23^{\circ}$ BTDC and $26^{\circ}$ BTDC and three different nozzles such as 3 hole, 4 hole and 5 hole are varied to analyze the performance and emission characteristics. From the test results, it could be observed that among three different injection timings $26^{\circ} \mathrm{BTDC}$ and among three different nozzles 5 hole nozzle gives higher efficiency and lower emissions as compared to other two injection timings and other two nozzles
\end{abstract}

Copy Right, IJAR, 2019,. All rights reserved.

\section{Introduction:-}

Increasing petroleum prices, increasing threat to the environment from exhaust emissions and global warming have generated interest in developing alternative non-petroleum fuels for engines [1]. The use of vegetable oil in engines is not a recent innovation. In the present scenario, oil has become a finite resource and its price tends to increase exponentially, as its reserves are fast depleting [2]. Recent report says that lower smoke levels and higher thermal efficiencies are offered more by the methyl ester of vegetable oils than neat vegetable oils [3]. Further, it has been reported that the thermal efficiency of the engine increases with an increase in the methanol fraction in diesel [4]. Intensive research is going on throughout the globe for a suitable diesel substitute [5].

In this race among different alternatives, vegetable oils have attained primary place as some of their physical, chemical and combustion related properties are nearly similar to that of diesel fuel. Vegetable oils can be used directly or can be blended with diesel to operate compression ignition engines [6]. As Thevetia Peruviana grows mainly in jungle area and also in waste and uncultivated land its cultivation would not produce any impact on food production but would in long way improve the environmental condition by massive afforestation. Thevetia Peruviana oil is non-edible vegetable oil, which is available in large quantities in India. In a country like India it is observed that biodiesel can be a viable alternative automotive fuel. Biodiesel is a fastest growing alternative fuel and 
India has better resources for its production [7]. The vegetable oils cannot be used directly in diesel engines as alternative fuel because of high viscosity of vegetable oils leads to problem in pumping and spray characteristics. The best way to use vegetable oils as fuel in diesel engines is to convert it into biodiesel [8]. It is a fact that biodiesel is a safer, more economical and infinitely more environmentally friendly than the conventional petroleum diesel that the majority of people currently use [9]. Thevetia Peruviana Biodiesel is a vegetable oil-based fuel that can be used to replace diesel fuel [10].

The use of diesel engines today depends on lowering toxic components emission to the atmosphere, such as carbon monoxide (CO), nitric oxides (NOx), hydrocarbons (HC) and particulate matter (PM). Considering the difficulties of proper control of the combustion process, some activities have been undertaken aiming at lowering its effects that is purifying exhaust gases. The fuel injection system is without any doubt one of the most important systems. It meters the fuel delivery according to engine requirements, it generates the high injection pressure required for fuel atomization, for air-fuel mixing and for combustion and it contributes to the fuel distribution in the combustion system hence it significantly affects engine performance emissions and noise [11].

Sayin et al. [11] found that, maximum Brake Thermal Efficiency (BTE) was obtained 0.289\% for the B0 and $28.6 \%$ for the B5 at $37.5 \mathrm{kPa}$ at original injector hole number and 26.2\% for B20, 25.4\% for B50 and $25.3 \%$ for B100 at 50 $\mathrm{kPa}$ and original injector hole number. The injector hole number have some effects on BTE. An aerodynamic interaction and turbulence seem to have competing effects on spray break up as the fuel injector hole number increases. The fuel drop size decreases if the injector hole number decreases with a decrease quantitative effect for a given set of jet conditions. The B0 fuel produced the highest BTE as $28.8 \%$. The higher of B0 operation can be attributed to its lower heating value. Increased injector hole number increased the BTE values for B50 and B100. The increase in BTE may be attributed to the more efficient utilization of the biodiesel fuel at higher injector hole number because of finer atomization of fuel.

Sharma et al. [12] found that, nozzle hole geometry had significant influences on droplet size penetration. Corresponding injection pressure, there was rise in thermal efficiency with increase in nozzle hole. That was due to increase in nozzle hole was responsible to rise in air fuel mixing, fuel vaporization and improved combustion and heat release rate. Thus, in view of that BTE rises with number of hole. BTE $26.65 \%$ and $26.18 \%$ was higher at NH2, 220 bar injection pressure, and full load and $80 \%$ load respectively. One of the nozzles with smaller orifices $(\varnothing 0.20$ $\mathrm{mm}$ ) had improved combustion for all of the test cases, resulting in an increase in fuel conversion efficiency compared to the reference nozzle $(\varnothing 0.28 \mathrm{~mm})$.

Varghese et al. [13] found that, BTE decreased with increase in the nozzle sizes. At 25\%, 50\%, 75\% load conditions B20 produced the maximum brake thermal efficiency with some exception. But at peak load condition, for all the three nozzles, diesel fuel produced the maximum break thermal efficiency.

Kumar [14] found that, break thermal efficiency of $23.5 \%$ for diesel and $25 \%$ for N60 for 9 hole nozzle, and $24 \%$ for diesel and $26.03 \%$ for N60 was obtained for 11 hole nozzle. The main reason for increase in the brake thermal efficiency may due to more homogeneous mixture formation and spray characteristics are maintains the presence of the oxygen in the biofuels.

Swamy et al. [15] found that, at fixed injection opening pressure (IOP) the highest brake thermal efficiency occurred for nozzle geometry with 5 hole having an orifice diameter of $0.3 \mathrm{~mm}$. That may be due to atomization, spray characteristics and mixing with air were better, resulting in improved combustion. The BTE was found to be $28.5 \%$ at $80 \%$ load and its maximum value obtained with 5 hole nozzle at an injection opening pressure of 205 bar. The BTE reported for 3 hole and 4hole nozzles were $24.80 \%$ and $27.56 \%$ at 205 bar respectively. Increased number of holes had not much effect on ignition delay, but the fuel-air mixing rate increases and hence the found results favored the 5 hole injector. Decreasing the size of holes from 0.3 to $0.2 \mathrm{~mm}$ of 5 hole injector, ensured better mixing of air and fuel inside the combustion chamber and further leads to better combustion and hence increased BTE was found. However with less than $0.2 \mathrm{~mm}$ the above effect was nullified as fuel droplets move faster than air associated with poor mixing further resulting in inferior engine performance.

Khandal et al. [16] found that, increasing the number of holes from 3 to 4 results in increased BTE for the same compression ratio and injection pressure but for higher values of injection pressure (240 bar), the BTE decreases. Honge oil methyl ester (HOME) being more viscous than diesel, the injected biodiesel droplets will be larger for the 
same injection pressure and compression ratio and consequently increased number of holes will make sure proper mixing of the injected fuel i.e. HOME with the surrounding air. Therefore, 4 hole injector operation results in an improved fuel combustion process. It also produces a comparatively more homogeneous charge, hence the heat release rate (HRR) during premixed combustion was at the peak level. Under identical conditions of injection timing (IT) and compression ratio, increasing the number of holes from 3 to 4 results in an increased BTE. That could be due to the fine jets of biodiesels emerging from the 4hole injector ensuring proper mixing of liquid fuel and the surrounding air resulting in improved combustion. For the same injection timing (IT) and injection pressure, increasing the number of holes from 3 to 4 results in increased BTE. As mentioned earlier, HOME was more viscous than diesel and hence increased number of holes will ensure proper mixing of the injected fuel with air, which ensures improved fuel combustion process.

Harari et al. [17-20] found that, for 3 hole nozzle, highest Peak pressure rise was found to be 59.63 bar for diesel fuel at $2.35 \mathrm{~kW}$ of BP and 230 bar injection pressure, 57.11 bar for B20 fuel at $3.52 \mathrm{~kW}$ of BP and 210 bar injection pressure and highest Indicated Mean Effective Pressure (IMEP) was found to be 15.63 bar for diesel fuel at $3.52 \mathrm{~kW}$ of BP and 230 bar injection pressure, 15.73 bar for B20 fuel at $3.52 \mathrm{~kW}$ of BP and 250 bar injection pressure. For 4 hole nozzle, highest Peak pressure rise was found to be 54.41 bar for diesel fuel at $3.52 \mathrm{~kW}$ of BP and $230 \mathrm{bar}$ injection pressure, 52.73 bar for B20 fuel at $3.52 \mathrm{~kW}$ of BP and 230 bar injection pressure and highest IMEP was found to be 15.54 bar for diesel fuel at $3.52 \mathrm{~kW}$ of BP and 250 bar injection pressure, 15.42 bar for B20 fuel at 3.52 $\mathrm{kW}$ of BP and 230 bar injection pressure. For 5 hole nozzle, highest Peak pressure rise was found to be 57.11 bar for diesel fuel at $1.17 \mathrm{~kW}$ of BP and 250 bar injection pressure, 55.59 bar for B20 fuel at $2.35 \mathrm{~kW}$ of BP and 210 bar injection pressure and highest IMEP was found to be 15.46 bar for diesel fuel at $3.52 \mathrm{~kW}$ of $\mathrm{BP}$ and $250 \mathrm{bar}$ injection pressure, 15.79 bar for B20 fuel at $3.52 \mathrm{~kW}$ of BP and 250 bar injection pressure [17].

For 3 hole nozzle, highest Peak pressure rise was found to be 62.83 bar for diesel fuel, 60.64 bar for B20 fuel and highest IMEP was found to be 16.31 bar for diesel fuel, 16.06 bar for B20 fuel at $26^{\circ}$ BTDC injection timing. For 4 hole nozzle, highest Peak pressure rise was found to be 57.28 bar for diesel fuel, 57.11 bar for B20 fuel and highest IMEP was found to be 15.69 bar for diesel fuel, 15.42 bar for B20 fuel at $26^{\circ}$ BTDC injection timing. For 5 hole nozzle, highest Peak pressure rise was found to be 59.30 bar for diesel fuel, 57.44 bar for B20 fuel and highest IMEP was found to be 15.16 bar for diesel fuel, 15.03 bar for B20 fuel at $26^{\circ} \mathrm{BTDC}$ injection timing [18].

Decreasing the size of holes of fuel injector ensured better mixing of air and fuel inside the combustion chamber and further leads to better combustion and hence increased BTE was found. With decreasing injector hole number fuel particle diameters will enlarge and ignition delay period during the combustion will increase. That situation causes an increase in the BSFC. On the other hand increasing injector hole number causes a shorter ignition delay period. So that possibilities of homogeneous mixing decrease and BSFC augments. Increasing the number of holes resulted in increased cylinder peak pressure. That could be attributed to better mixing of the injected liquid fuel emerging from the higher hole injector with the surrounding air and thereby providing near stoichiometric air-to fuel ratio inside the combustion chamber. As the number of nozzle holes were increased the heat release rate during the premixed combustion phase and the mixing controlled combustion phase tend to increase. $\mathrm{CO}$ emissions were found to be lower for decreasing injector hole sizes as the wall impingement with diesel was less compared to that with larger hole size. However higher hole size injectors leads to deposition of fuel on the combustion chamber walls. Hence higher $\mathrm{CO}$ emissions were found to be more with larger size hole injector. Increasing the number of holes in the injector resulted in decreased HC. That could be attributed to improved mixing of liquid fuel and the surrounding air inside the combustion chamber with a larger size hole injector and hence resulting in complete combustion. NOx emissions increases with the increase in the number of injector holes due to faster combustion and higher temperatures reached in the cycle. The reason for increased NOx with increased size of holes could be due to better combustion prevailing inside the engine cylinder and more heat released during premixed combustion. Decreased hole size ensures improved air-fuel mixing which results in enhanced combustion that results in reduced smoke opacity levels [19].

For 3 hole nozzle, maximum BTE was found to be $24.32 \%$ for diesel, $26.82 \%$ for B20 fuel and minimum BSFC was found to be $0.352 \mathrm{~kg} / \mathrm{kW}-\mathrm{hr}$ for diesel, $0.328 \mathrm{~kg} / \mathrm{kW}-\mathrm{hr}$ for B20 fuel at $3.52 \mathrm{~kW}$ of BP and at 230 bar injection pressure. For 4 hole nozzle, maximum BTE was found to be $13.54 \%$ for diesel, 14.64\% for B20 fuel and minimum BSFC was found to be $0.632 \mathrm{~kg} / \mathrm{kW}-\mathrm{hr}$ for diesel, $0.601 \mathrm{~kg} / \mathrm{kW}-\mathrm{hr}$ for B20 fuel at $2.94 \mathrm{~kW}$ of BP and at $230 \mathrm{bar}$ injection pressure. For 5 hole nozzle, maximum BTE was found to be $21.28 \%$ for diesel, $22.69 \%$ for B20 fuel and 
minimum BSFC was found to be $0.402 \mathrm{~kg} / \mathrm{kW}$-hr for diesel, $0.388 \mathrm{~kg} / \mathrm{kW}-\mathrm{hr}$ for B20 fuel at $3.52 \mathrm{~kW}$ of BP and at 230 bar injection pressure [20].

\section{Objectives:-}

1. To study Thevetia Peruviana blends in single cylinder diesel engine as an alternative fuel.

2. To increase the Brake Thermal Efficiency and decreasing Brake Specific Fuel Consumption along with emissions of diesel engine.

3. To study the best suitable injection timing and nozzle hole for existing engine in terms of performance and emissions.

\section{Methodology:-}

1. Collection of raw oil of Thevetia Peruviana.

2. Transesterification reaction to convert raw oil into biodiesel.

3. Prepare blends with diesel such as B0, B20, B40, B60, B80 and B100.

4. Determine fuel properties such as Density, Kinematic viscosity, Flash point, Fire point and Calorific value.

5. Single Cylinder, Water Cooled, 4-Stroke, 1500 RPM, $5.2 \mathrm{~kW}, 230$ bar Injection Pressure, $23^{\circ}$ BTDC Injection Timing, Hemispherical Combustion Chamber, 3 Hole Nozzle, 17.5:1 Compression Ratio engine is used for the study.

6. Change the injection timings such as $20^{\circ} \mathrm{BTDC}, 23^{\circ} \mathrm{BTDC}$ and $26^{\circ} \mathrm{BTDC}$.

7. Determine performance and emission characteristics Brake Thermal Efficiency, Brake Specific Fuel Consumption, Total Fuel Consumption, HC, CO, NOx, Smoke emissions.

8. Compare the results and find the optimum injection timing for engine.

9. Keeping optimum injection timing change nozzle holes such as 3 hole, 4 hole and 5 hole.

10. Determine performance and emission characteristics Brake Thermal Efficiency, Brake Specific Fuel Consumption, Total Fuel Consumption, HC, CO, NOx, Smoke emissions.

11. Compare the results and find the optimum nozzle for engine.

\section{Transesterification Reaction}

It is most commonly used and important method to reduce the viscosity of vegetable oils. In this process triglyceride reacts with three molecules of alcohol in the presence of a catalyst producing a mixture of fatty acids, alkyl ester and glycerol. The process of removal of all the glycerol and the fatty acids from the vegetable oil in the presence of a catalyst is called esterification. The Figure 2 shows the transesterification process in which the upper layer forms the ester and lower layer forms the glycerol. The parameter such as temperature, molar ratio and catalyst concentration that affect the transesterification of raw oil were optimized initially. The transesterification set up houses $2 \mathrm{~L}$ capacity, round bottom flask provided with three necks that was placed in a water container for heating the oil. A heater with a temperature regulator was placed in the round bottom flask. A high speed motor with a magnetic stirrer was used for vigorous mixing of the oil. In the transesterification process triglycerides of raw oil reacts with methyl alcohol in the presence of catalyst $(\mathrm{NaOH})$ to produce a fatty acid ester and glycerol. In this process $1000 \mathrm{~g}$ raw oil, $230 \mathrm{~g}$ methanol and $8 \mathrm{~g}$ sodium hydroxide pellets were placed in the round bottom flask. The contents were heated to $70^{\circ} \mathrm{C}$ and stirred vigorously for one hour to promote ester formation. The mixture was next transferred to a separating funnel and allowed to settle under gravity overnight. The upper layer in the separating funnel consists of ester whist the lower layer is glycerol which was removed. The separated ester with $250 \mathrm{~g}$ hot water and allowed to settle under gravity for 24 hours. Water washing separates residual fatty acids and catalyst and these were removed using a separating funnel. Finally the moisture from the ester was removed by adding silica gel crystals. Various biodiesel-diesel blends B10, B20, B30, B40 and B50 were prepared for the experimental work. 


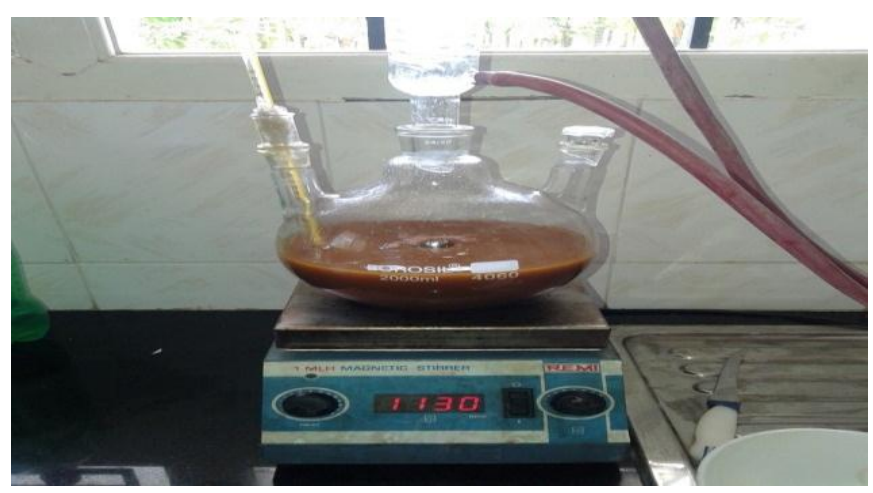

Fig 1:-Three mouth flask.

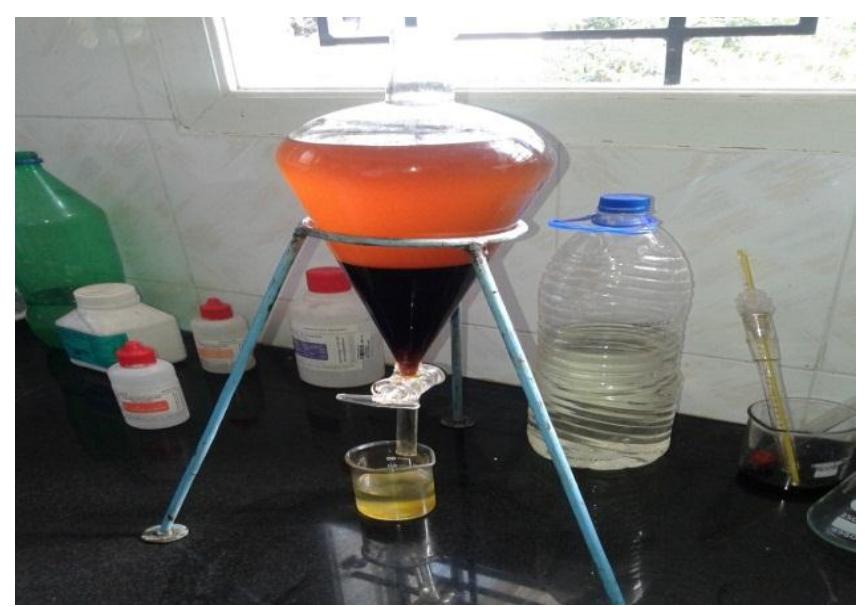

Fig 2:-Separation of glycerin and biodiesel

Properties Of Fuels

Table 1:-Properties of fuels

\begin{tabular}{|c|c|c|c|c|c|c|}
\hline Property & B0 & B20 & B40 & B60 & B80 & B100 \\
\hline Density $\left(\mathrm{kg} / \mathrm{m}^{3}\right)$ & 829 & 839 & 842 & 846 & 849 & 856 \\
\hline Viscosity at $40^{\circ} \mathrm{C}(\mathrm{CSt})$ & 3.52 & 3.96 & 4.22 & 4.71 & 4.89 & 5.35 \\
\hline Flash Point $\left({ }^{\circ} \mathrm{C}\right)$ & 53 & 77 & 83 & 87 & 98 & 122 \\
\hline Fire Point $\left({ }^{\circ} \mathrm{C}\right)$ & 59 & 86 & 92 & 95 & 112 & 139 \\
\hline Calorific Value $(\mathrm{MJ} / \mathrm{kg})$ & 42.19 & 41.45 & 40.92 & 40.31 & 39.98 & 39.25 \\
\hline
\end{tabular}

\section{Changing Injection Timing}

The fuel injection timing can be varied by adjusting shims provided between fuel pump and engine body which is as shown in Fig 3.

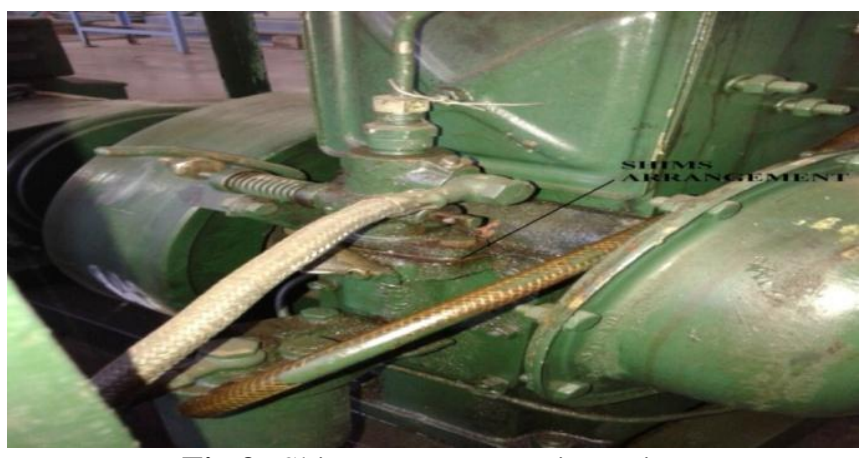

Fig 3:-Shims arrangement in engine 


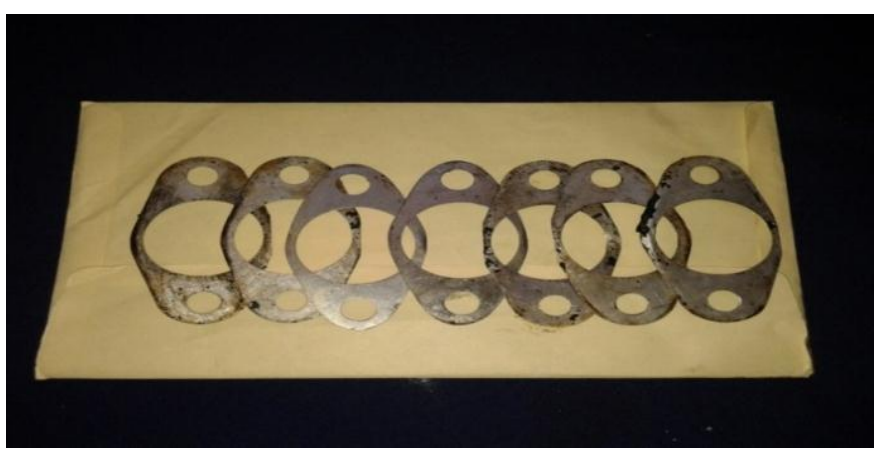

Nozzle Spray Pattern

Fig 4:-Photographic view of shims

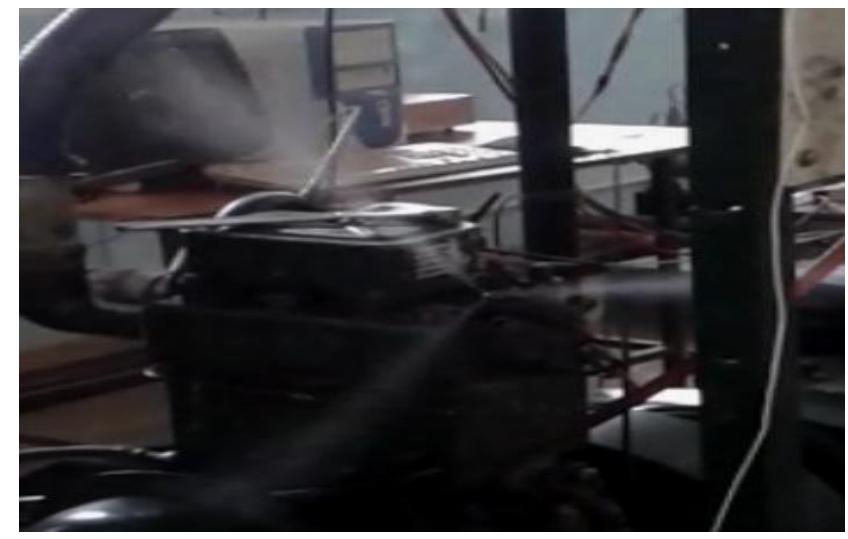

Fig 5:-Three Hole Nozzle

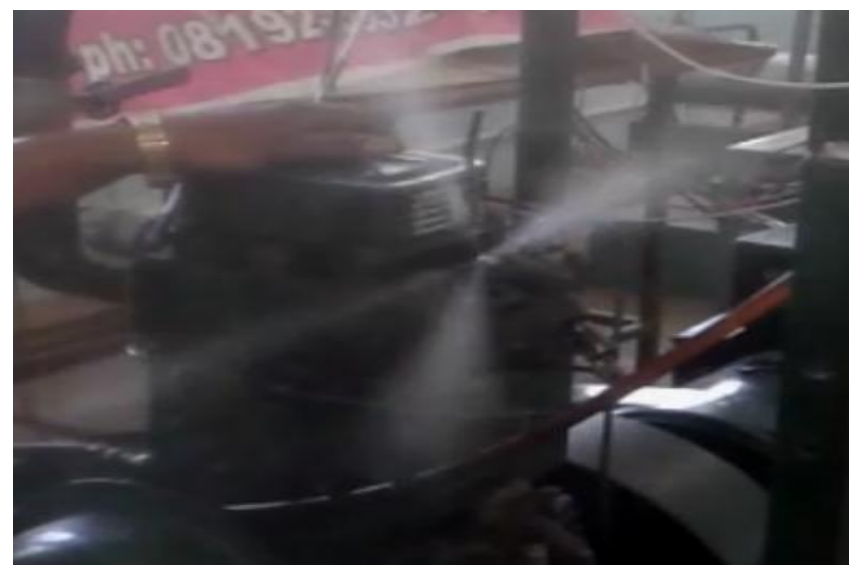

Fig 6:-Four Hole Nozzle 


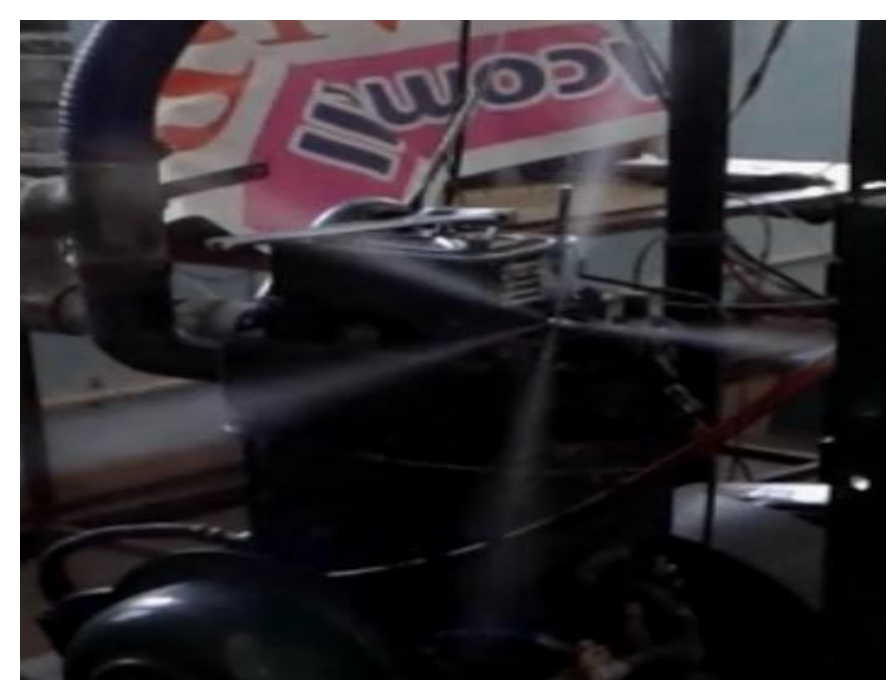

Fig 7:-Five Hole Nozzle

\section{Experimental Setup}

A single cylinder, direct injection, four-stroke, water cooled, Compression Ignition (CI) engine is used in the experimental study. The fuel flow rate was measured by noting down the time taken for the consumption of a known quantity of fuel (10cc) from a burette. The viscosity of raw as well as esterified oil was measured by red wood viscometer, density by hydrometer, calorific value by bomb calorimeter, flash and fire point by open cup method. Initially, before starting experimental tests, the engine was made to run under ideal condition as warm up phase and then the tests were conducted. The engine was started and allowed to warm-up for about 10 minutes. The engine was tested under five discrete part load conditions i.e. $20 \%, 40 \%, 60 \%, 80 \%$ and $100 \%$.

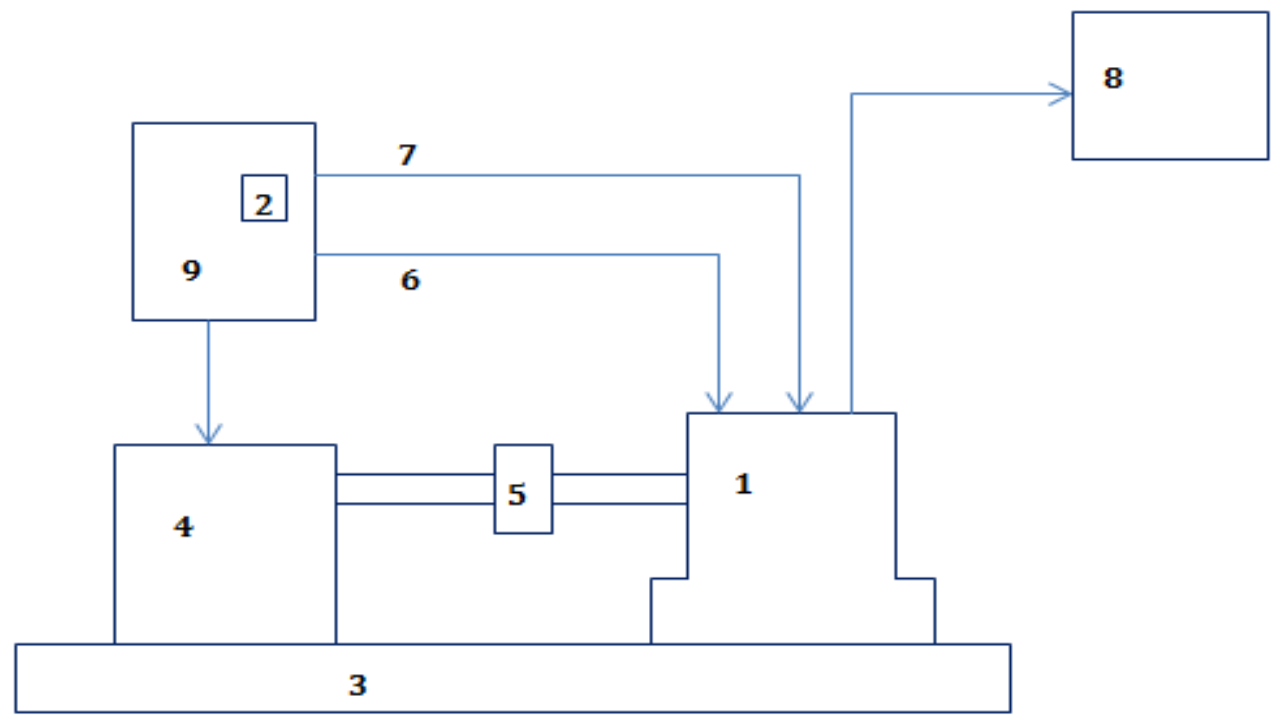

Fig 8:-Experimental Setup

1-Diesel engine, 2-Burette for fuel measurement, 3-Base, 4-Dynamometer, 5-Coupling, 6-Air supply line, 7-Fuel spply line, 8-Exhaust gas analyzer, 9-Control panel.

\section{Engine Specifications}

Table 2:-Engine parameters

\begin{tabular}{|l|l|}
\hline Engine Parameter & Specifications \\
\hline Engine Type & Kirloskar \\
\hline
\end{tabular}




\begin{tabular}{|l|l|}
\hline No. of Strokes & 4 \\
\hline No. of Cylinders & 1 \\
\hline Type of Cooling & Water Cooling \\
\hline Type of Injection & Direct Injection \\
\hline Bore & $87.5 \mathrm{~mm}$ \\
\hline Stroke & $110 \mathrm{~mm}$ \\
\hline Compression Ratio & $17.5: 1$ \\
\hline Rated Power & $5.2 \mathrm{~kW}$ \\
\hline Rated Speed & $1500 \mathrm{rpm}$ \\
\hline Injection Pressure & $230 \mathrm{bar}$ \\
\hline Injection Timing & $23^{\circ} \mathrm{BTDC}$ \\
\hline
\end{tabular}

Results and discussion:-

Optimization of injection timing

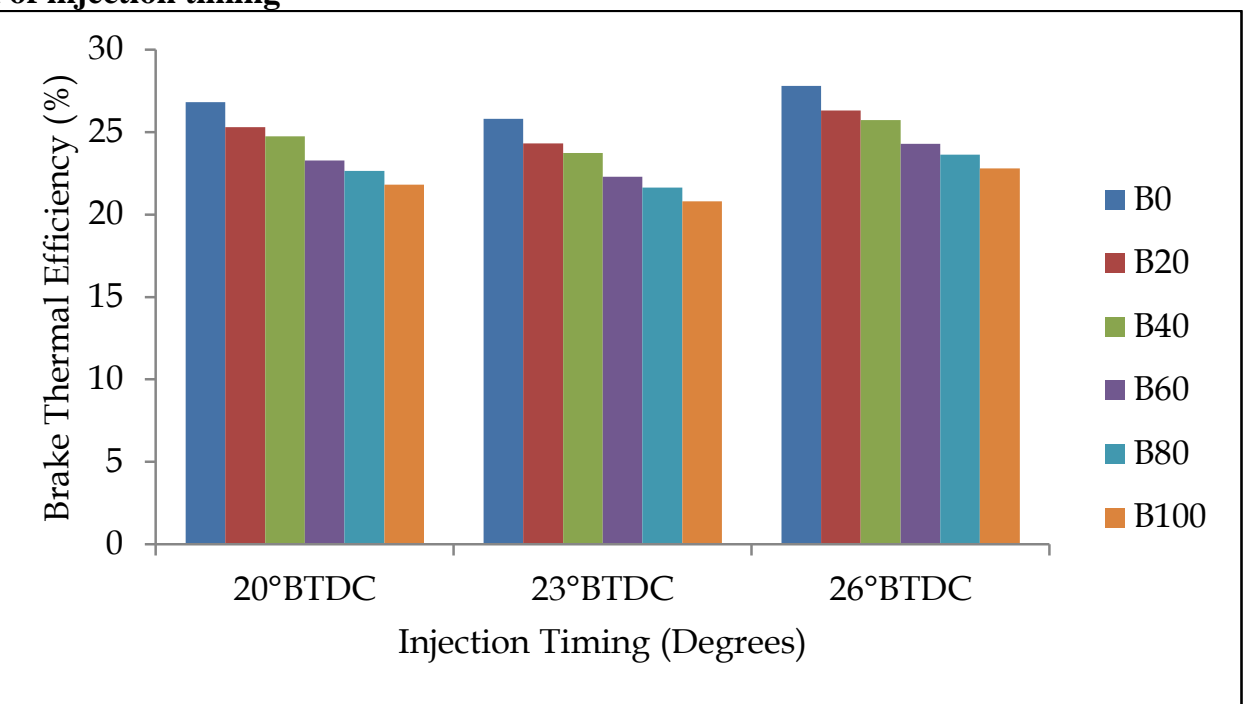

Fig 9:-Variation of brake thermal efficiency with injection timing

Among all the blends tested $\mathrm{B} 0$ blend gives higher brake thermal efficiency because of higher calorific value of the B0 blend. Among different injection timings tested $26^{\circ} \mathrm{BTDC}$ gives the higher brake thermal efficiency because with the advancing in injection timing from $20^{\circ} \mathrm{BTDC}$ to $26^{\circ} \mathrm{BTDC}$ there is much time availability for the mixing of fuel and air and hence brake thermal efficiency increases. 


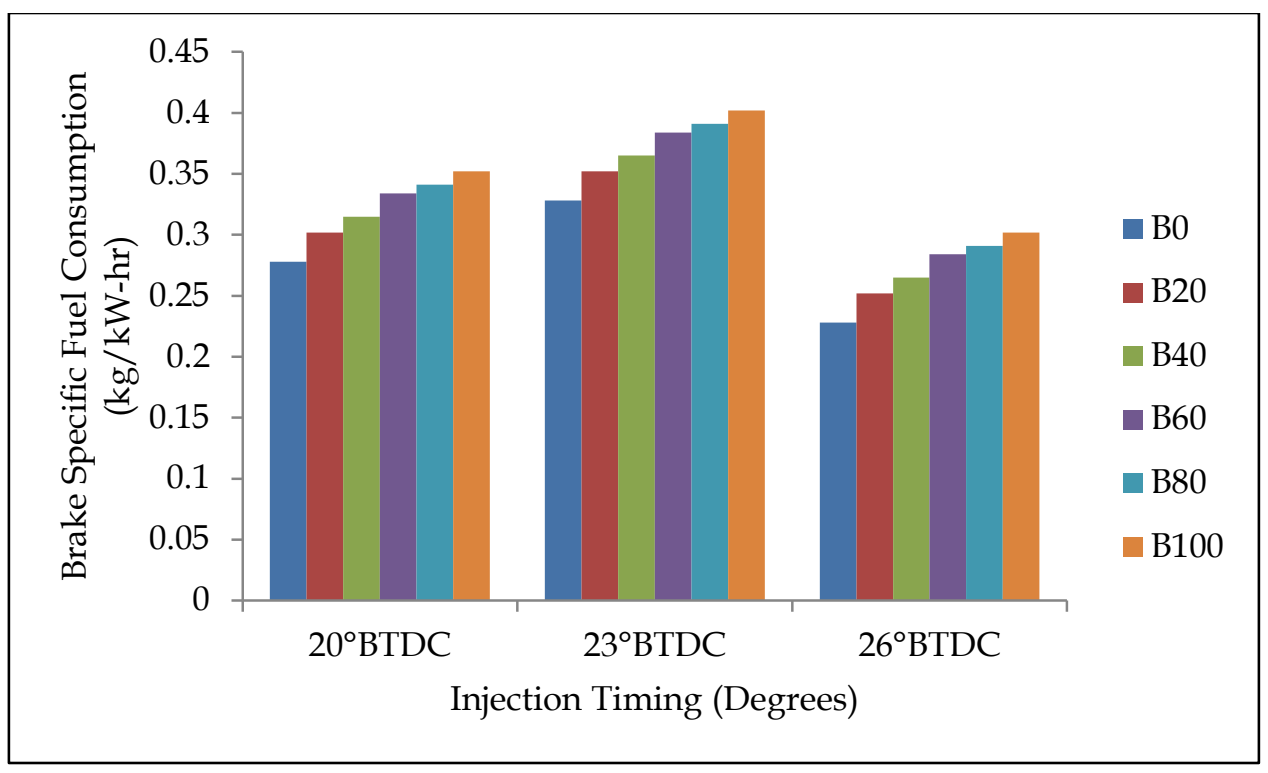

Fig 10:-Variation of brake specific fuel consumption with injection timing

Among all the blends tested B0 blend gives lower brake specific fuel consumption because of lower viscosity of the B0 blend. Among different injection timings tested $26^{\circ} \mathrm{BTDC}$ gives the lower brake specific fuel consumption because with the advancing in injection timing from $20^{\circ} \mathrm{BTDC}$ to $26^{\circ} \mathrm{BTDC}$ there is much time availability for the mixing of fuel and air and hence brake specific fuel consumption decreases.

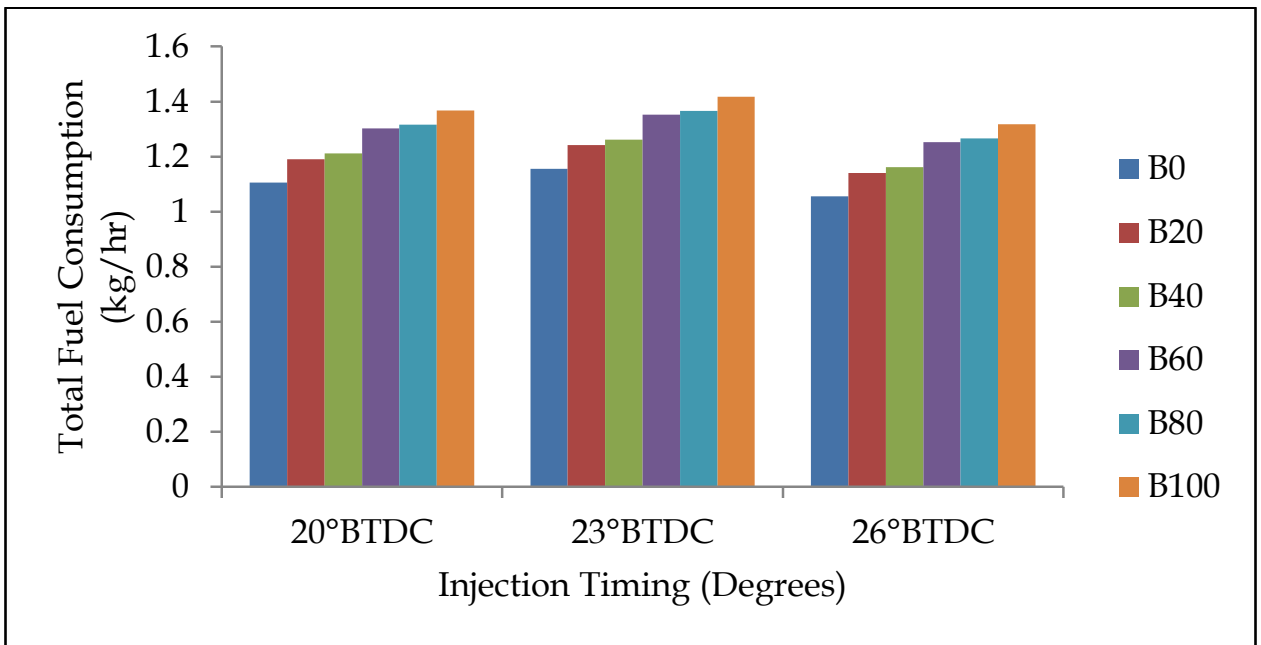

Fig 11:-Variation of total fuel consumption with injection timing

Among all the blends tested B0 blend gives lower total fuel consumption because of lower viscosity of the B0 blend. Among different injection timings tested $26^{\circ} \mathrm{BTDC}$ gives the lower total fuel consumption because with the advancing in injection timing from $20^{\circ} \mathrm{BTDC}$ to $26^{\circ} \mathrm{BTDC}$ there is much time availability for the mixing of fuel and air and hence total fuel consumption decreases. 


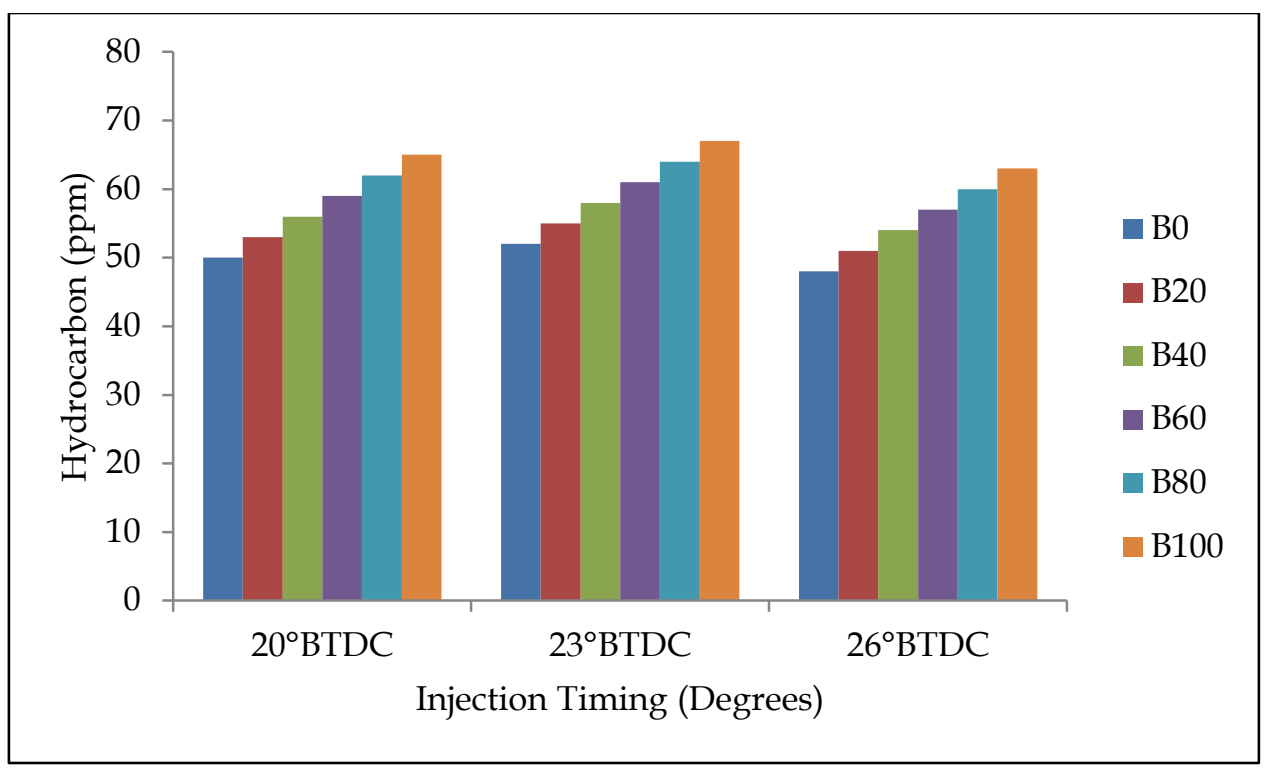

Fig 12:-Variation of hydrocarbon emissions with injection timing

Among all the blends tested $\mathrm{B} 0$ blend gives lower $\mathrm{HC}$ emissions because of better mixing of the $\mathrm{B} 0$ blend with the air. Among different injection timings tested $26^{\circ} \mathrm{BTDC}$ gives the lower $\mathrm{HC}$ emissions because with the advancing in injection timing from $20^{\circ} \mathrm{BTDC}$ to $26^{\circ} \mathrm{BTDC}$ there is much time availability for the mixing of fuel and air and hence $\mathrm{HC}$ emissions decreases.

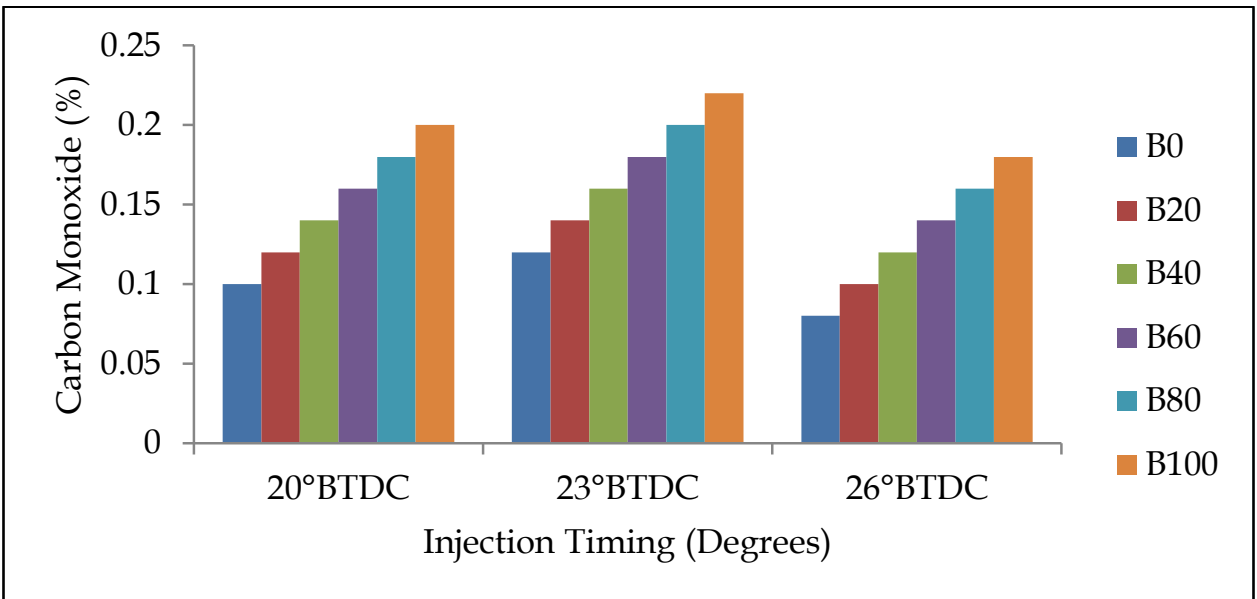

Fig 13:-Variation of carbon monoxide emissions with injection timing

Among all the blends tested $\mathrm{B} 0$ blend gives lower $\mathrm{CO}$ emissions because of better mixing of the $\mathrm{B} 0$ blend with the air. Among different injection timings tested $26^{\circ} \mathrm{BTDC}$ gives the lower $\mathrm{CO}$ emissions because with the advancing in injection timing from $20^{\circ} \mathrm{BTDC}$ to $26^{\circ} \mathrm{BTDC}$ there is much time availability for the mixing of fuel and air and hence $\mathrm{CO}$ emissions decreases. 


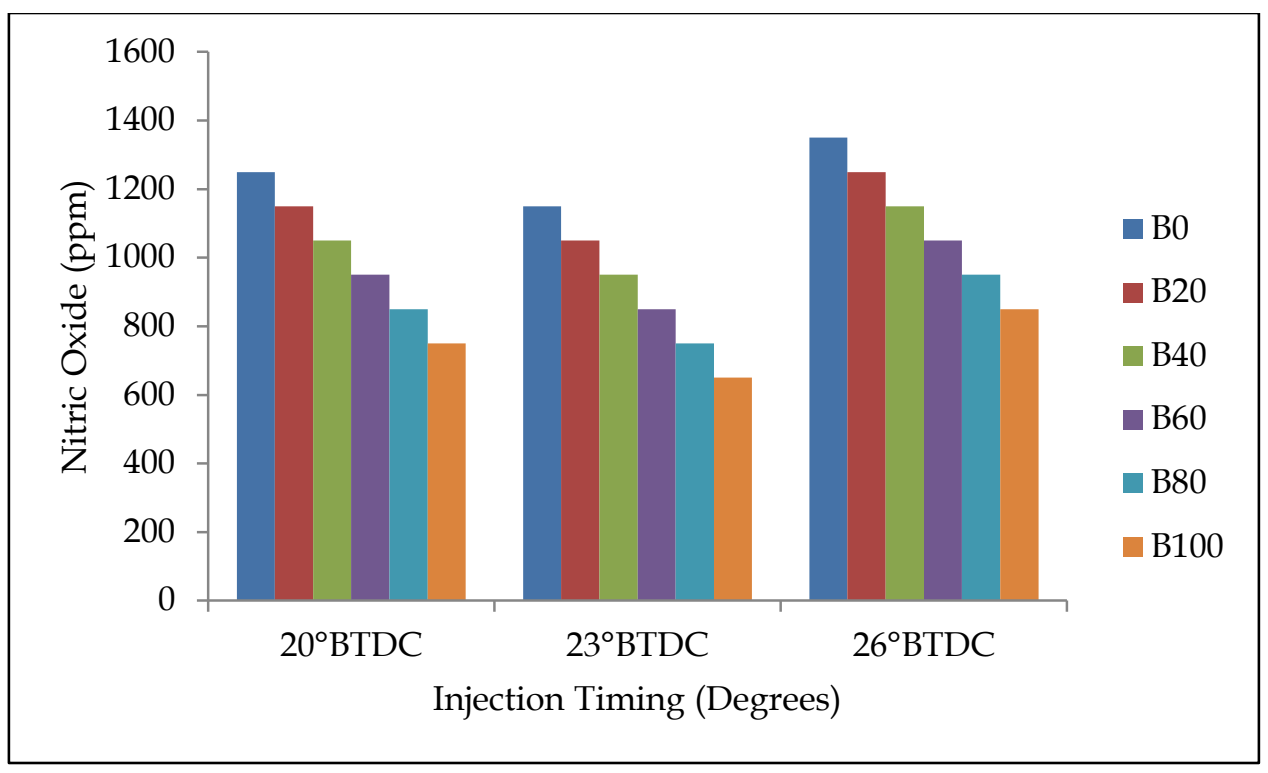

Fig 14:-Variation of nitric oxide emissions with injection timing

Among all the blends tested B0 blend gives higher NOx emissions because of higher calorific value of the B0 blend. Among different injection timings tested $26^{\circ}$ BTDC gives the higher NOx emissions because with the advancing in injection timing from $20^{\circ} \mathrm{BTDC}$ to $26^{\circ} \mathrm{BTDC}$ there is much time availability for the mixing of fuel and air and hence NOx emissions increases.

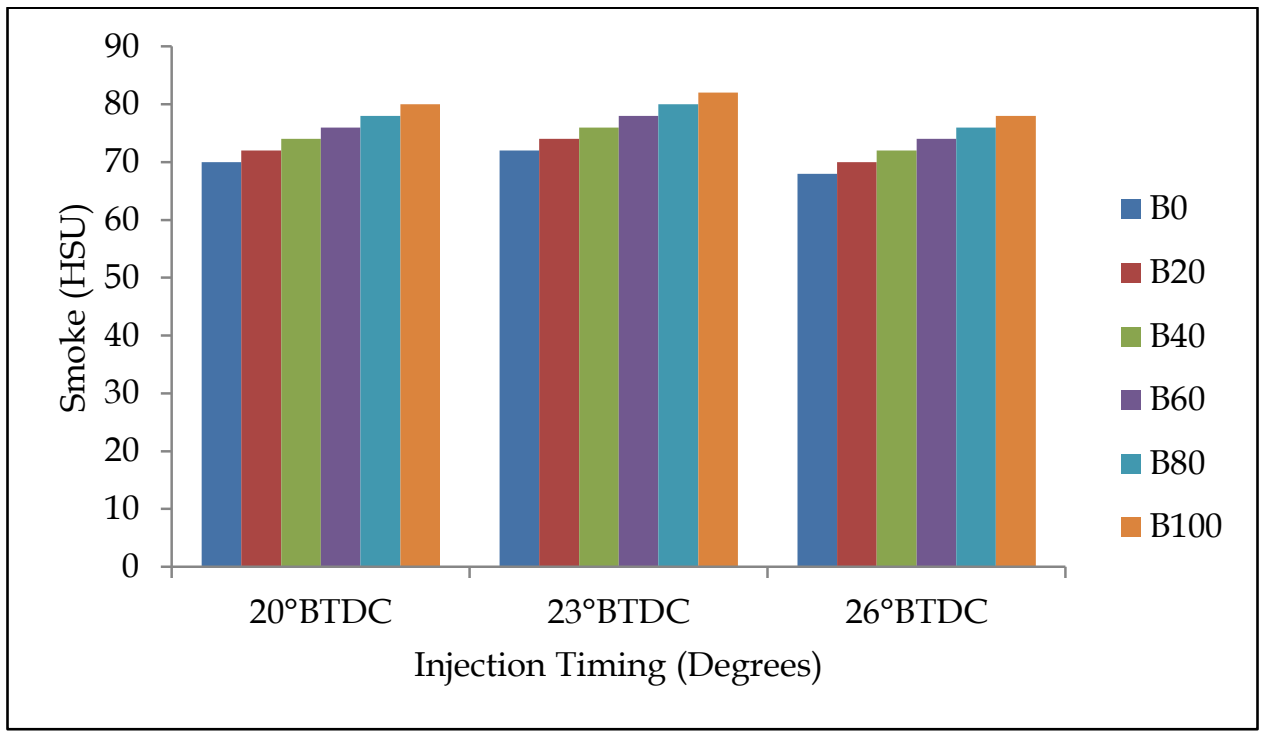

Fig 15:-Variation of smoke emissions with injection timing

Among all the blends tested $\mathrm{B} 0$ blend gives lower smoke emissions because of better mixing of the $\mathrm{B} 0$ blend with the air. Among different injection timings tested $26^{\circ} \mathrm{BTDC}$ gives the lower smoke emissions because with the advancing in injection timing from $20^{\circ} \mathrm{BTDC}$ to $26^{\circ} \mathrm{BTDC}$ there is much time availability for the mixing of fuel and air and hence smoke emissions decreases. 
Optimization Of Nozzle Hole Geometry

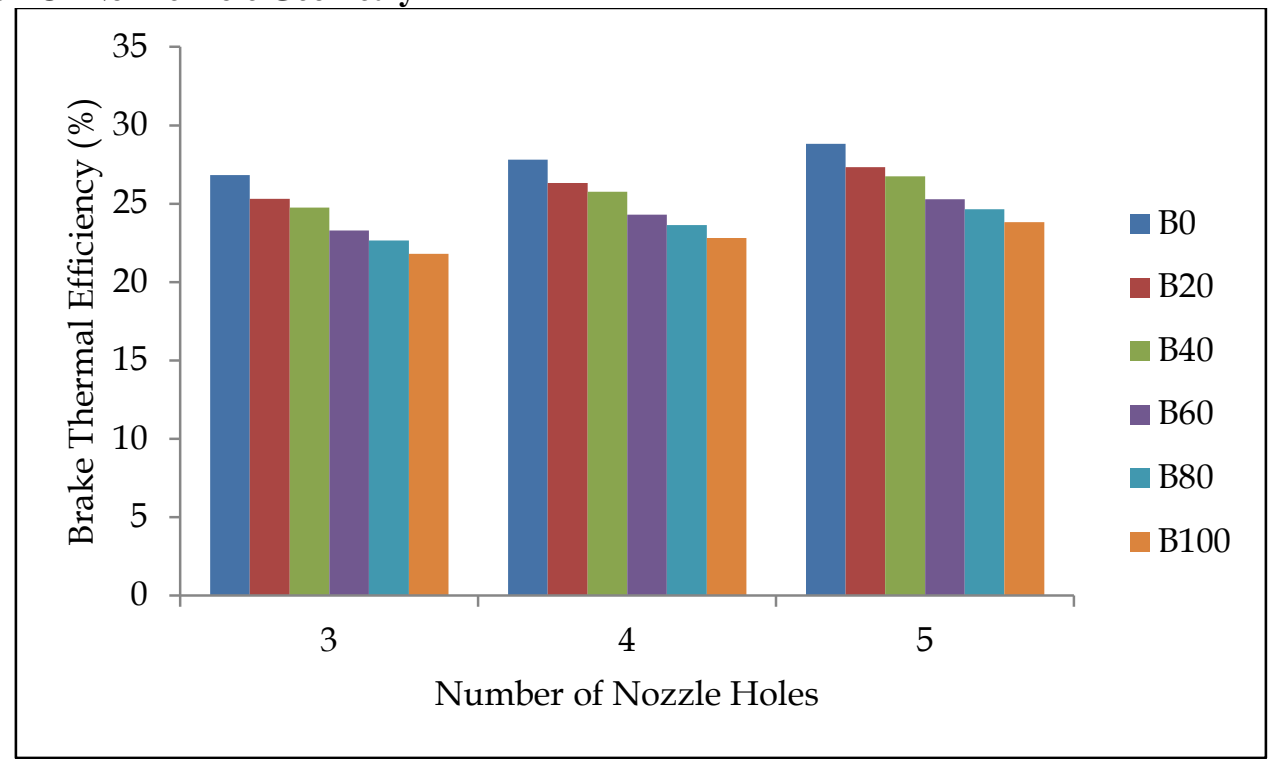

Fig 16:-Variation of Brake Thermal Efficiency with Number of Nozzle Holes

Among all the blends tested B0 blend gives higher brake thermal efficiency because of higher calorific value of the B0 blend. Among different nozzles tested 5 hole nozzle gives the higher brake thermal efficiency because diameter of nozzle holes decreases so that area of nozzle holes also decreases. This results into lower fuel consumption and higher thermal efficiency. For 4 hole nozzle the brake thermal efficiency decreases because the spray pattern of 4 hole nozzle was irregular so that maximum amount of fuel was impinged on the cylinder wall and hence brake thermal efficiency decreased.

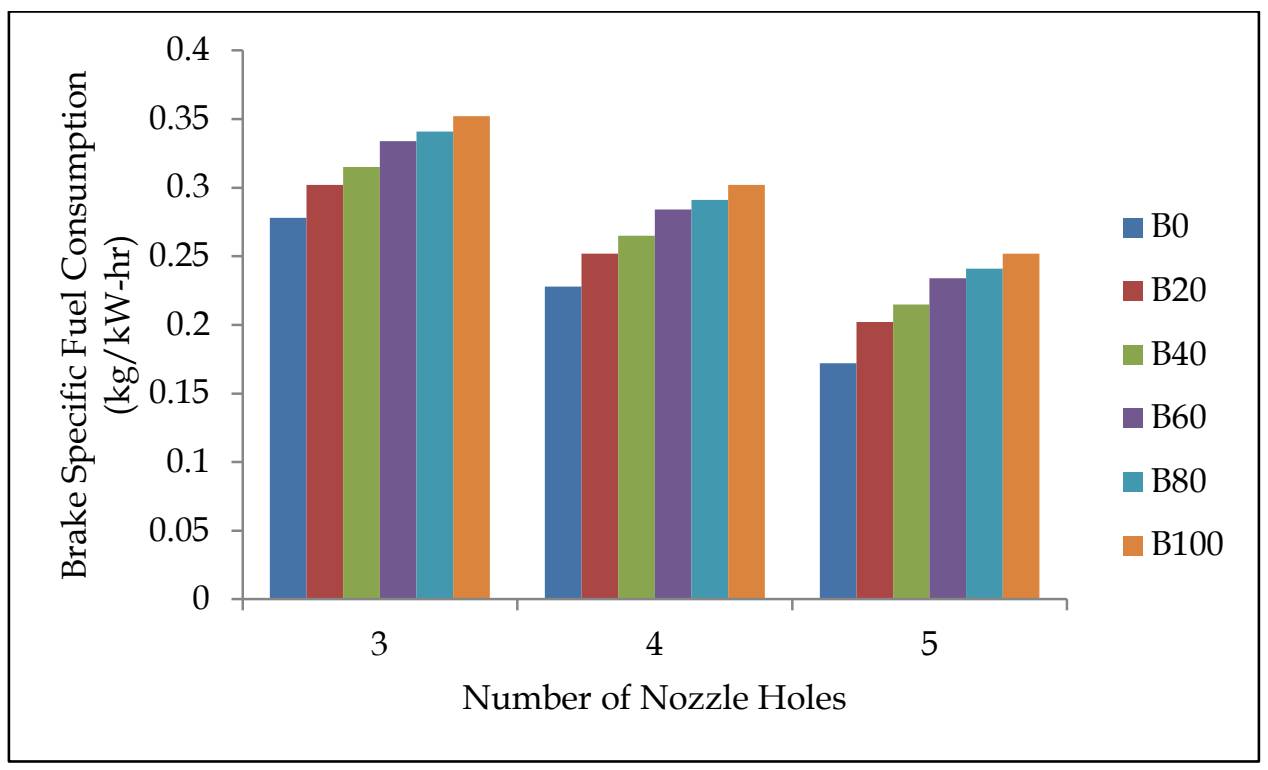

Fig 17:-Variation of Brake Specific Fuel Consumption with Number of Nozzle Holes

Among all the blends tested $\mathrm{B} 0$ blend gives lower brake specific fuel consumption because of higher calorific value of the B0 blend. Among different nozzles tested 5 hole nozzle gives the lower brake specific fuel consumption because diameter of nozzle holes decreases so that area of nozzle holes also decreases. This results into lower fuel consumption and higher thermal efficiency. For 4 hole nozzle the brake specific fuel consumption increases because the spray pattern of 4 hole nozzle was irregular so that maximum amount of fuel was impinged on the cylinder wall and hence brake specific fuel consumption increased. 


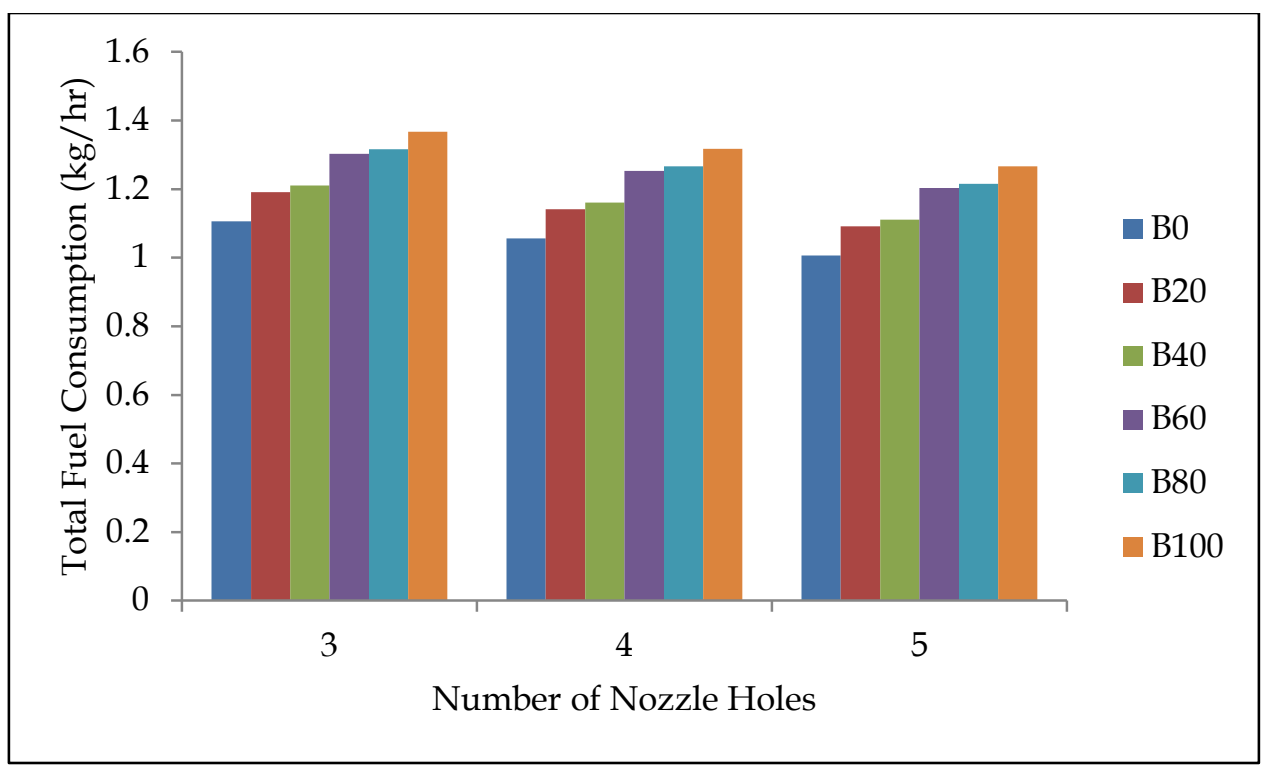

Fig 18:-Variation of Total Fuel Consumption with Number of Nozzle Holes

Among all the blends tested B0 blend gives lower total fuel consumption because of higher calorific value of the B0 blend. Among different nozzles tested 5 hole nozzle gives the lower total fuel consumption because diameter of nozzle holes decreases so that area of nozzle holes also decreases. This results into lower fuel consumption and higher thermal efficiency. For 4 hole nozzle the total fuel consumption increases because the spray pattern of 4 hole nozzle was irregular so that maximum amount of fuel was impinged on the cylinder wall and hence total fuel consumption increased.

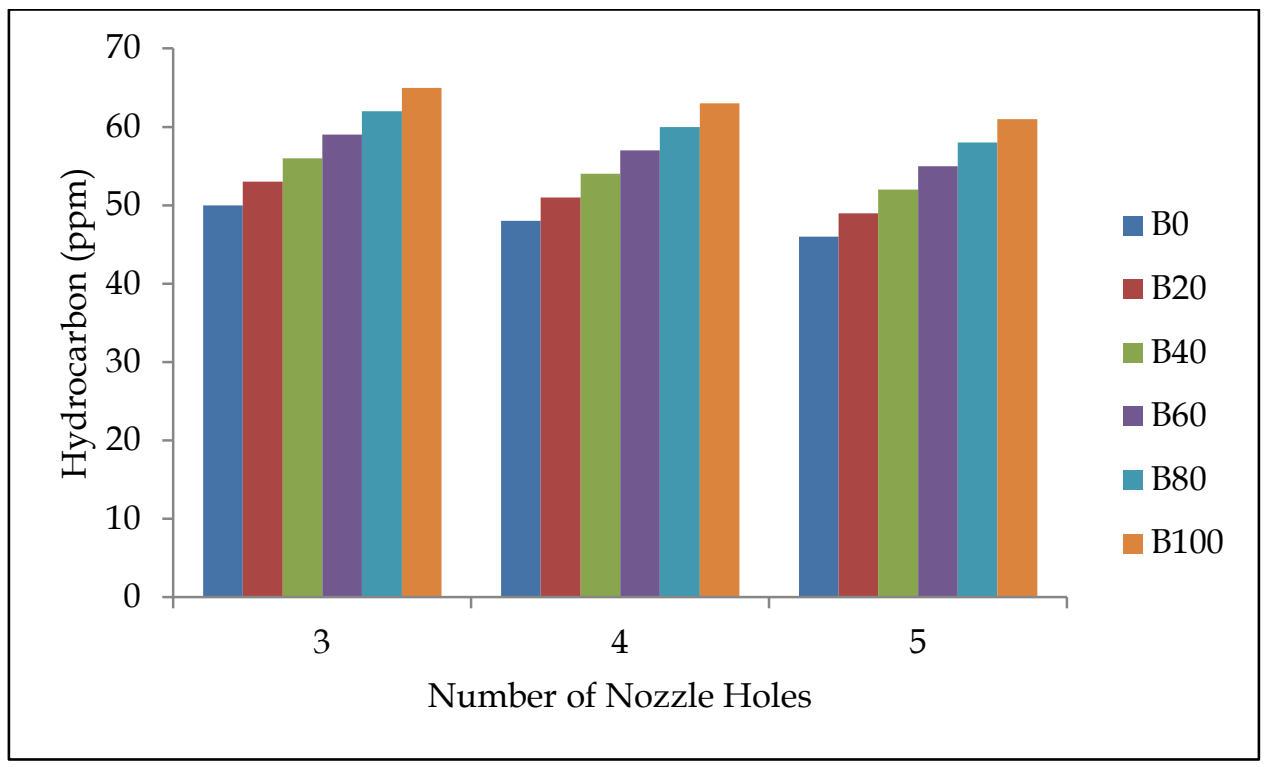

Fig 19:-Variation of Hydrocarbon Emissions with Number of Nozzle Holes

Among all the blends tested B0 blend gives lower hydrocarbon emission because of higher calorific value of the B0 blend. Among different nozzles tested 5 hole nozzle gives the lower hydrocarbon emission because diameter of nozzle holes decreases so that area of nozzle holes also decreases. This results into fuel consumption and higher thermal efficiency and also lower hydrocarbon emission. For 4 hole nozzle the hydrocarbon emission increases because the spray pattern of 4 hole nozzle was irregular so that maximum amount of fuel was impinged on the cylinder wall and hence hydrocarbon emission increased. 


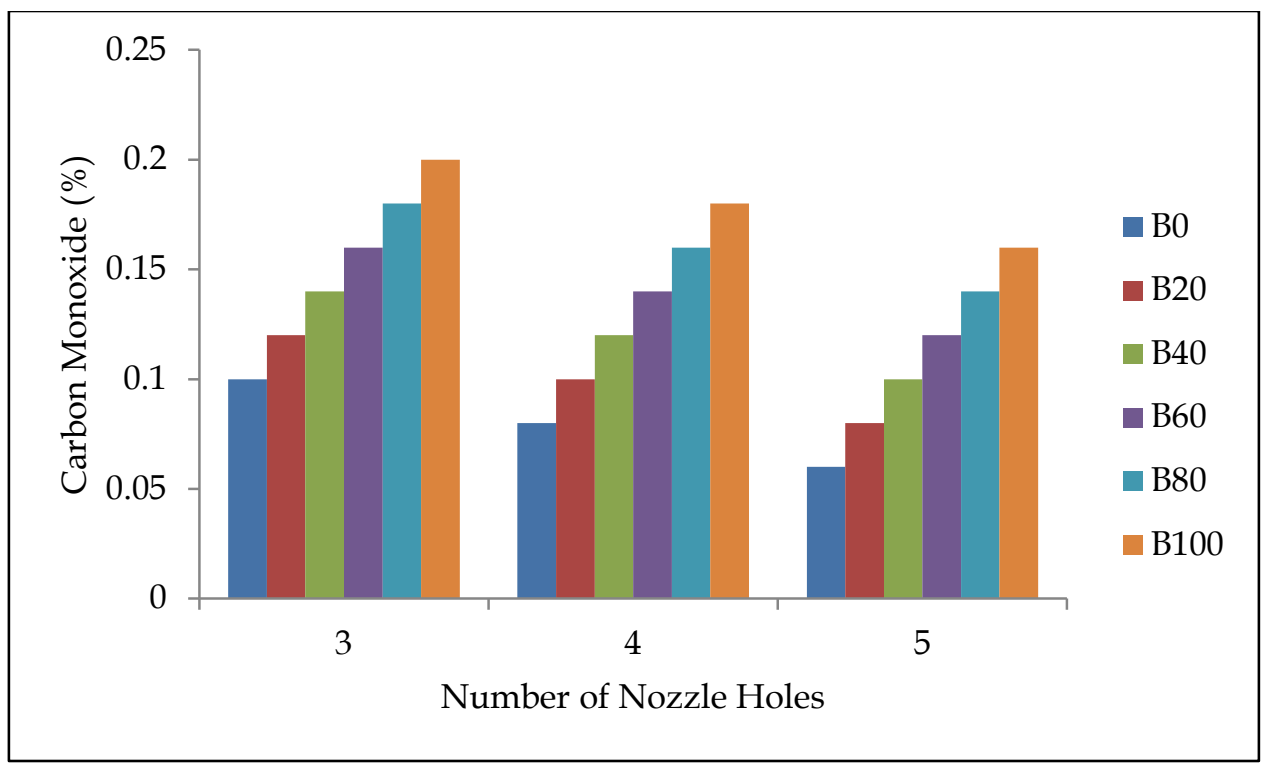

Fig 20:-Variation of Carbon Monoxide Emissions with Number of Nozzle Holes

Among all the blends tested B0 blend gives lower carbon monoxide emission because of higher calorific value of the B0 blend. Among different nozzles tested 5 hole nozzle gives the lower carbon monoxide emission because diameter of nozzle holes decreases so that area of nozzle holes also decreases. This results into fuel consumption and higher thermal efficiency and also lower carbon monoxide emission. For 4 hole nozzle the carbon monoxide emission increases because the spray pattern of 4 hole nozzle was irregular so that maximum amount of fuel was impinged on the cylinder wall and hence carbon monoxide emission increased.

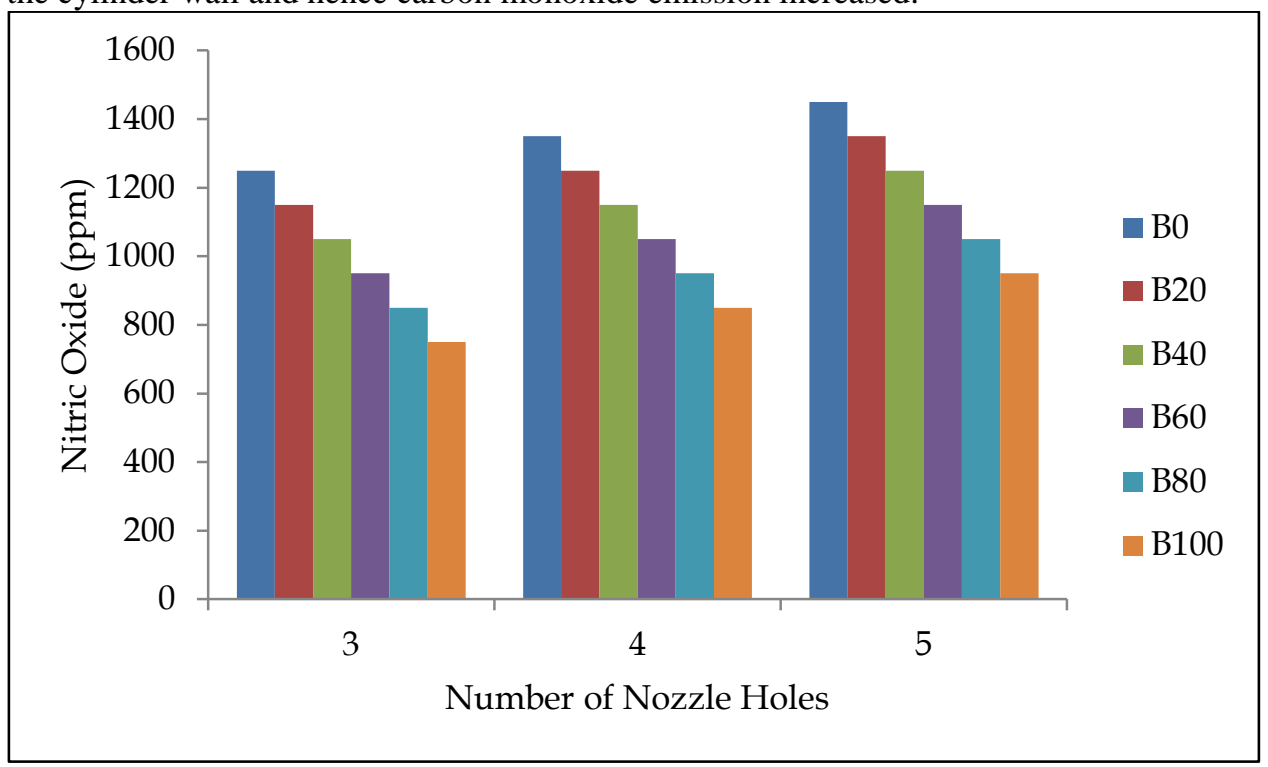

Fig 21:-Variation of Nitrogen Oxide Emissions with Number of Nozzle Holes

Among all the blends tested $\mathrm{B} 0$ blend gives higher nitrogen oxide emission because of higher calorific value of the B0 blend. Among different nozzles tested 5 hole nozzle gives the higher nitrogen oxide emission because diameter of nozzle holes decreases so that area of nozzle holes also decreases. This results into fuel consumption and higher thermal efficiency and also higher nitrogen oxide emission. For 4 hole nozzle the nitrogen oxide emission decreases because the spray pattern of 4 hole nozzle was irregular so that maximum amount of fuel was impinged on the cylinder wall and hence nitrogen oxide emission decreased. 


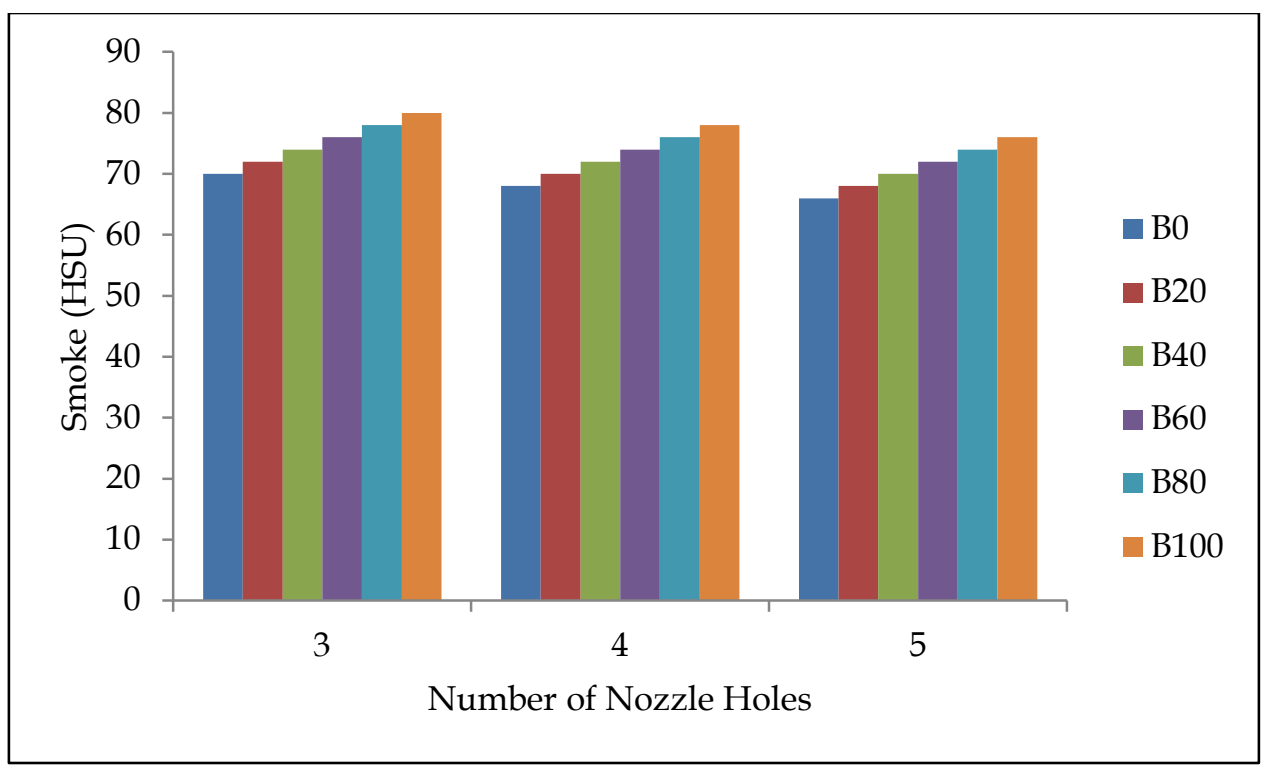

Fig 22:-Variation of Smoke Emissions with Number of Nozzle Holes

Among all the blends tested B0 blend gives lower smoke emission because of higher calorific value of the B0 blend. Among different nozzles tested 5 hole nozzle gives the lower smoke emission because diameter of nozzle holes decreases so that area of nozzle holes also decreases. This results into fuel consumption and higher thermal efficiency and also lower smoke emission. For 4 hole nozzle the smoke emission increases because the spray pattern of 4 hole nozzle was irregular so that maximum amount of fuel was impinged on the cylinder wall and hence smoke emission increased.

\section{Conclusions:-}

1. The brake thermal efficiency of biodiesel blends was found to be lower compared to diesel at all power output.

2. Brake specific fuel consumption for biodiesel blends of biodiesel blends is higher when compared with diesel.

3. Total fuel consumption for biodiesel blends is more as compared to diesel.

4. Hydrocarbon and carbon monoxide emissions for biodiesel are higher as compared to diesel.

5. Nitrogen oxide emissions are lower for biodiesel blends as compared to diesel.

6. Among the biodiesel blends tested, B20 gave the best performance with reduced emissions.

7. Hence $\mathrm{B} 20$ blends are recommended for existing diesel engine.

8. At all injection timings tested $26^{\circ} \mathrm{BTDC}$ and 5 hole nozzle gives higher brake thermal efficiency, lower brake specific fuel consumption, lower hydrocarbon and carbon monoxide emissions and higher nitrogen oxide emissions.

9. Hence $26^{\circ} \mathrm{BTDC}$ injection timing and 5 hole nozzle is recommended for existing diesel engine.

\section{References:-}

1. A.R.Pradeep, K.Annamalai, S.R.Prem, "Influence of Injection Timing on Emission Parameters of Adelfa Biodiesel (Nerium Oil Methyl Ester - NOME) Fuelled DI CI Engine", International Journal of Innovative Technology and Research, 2013, 1(1), 99-102.

2. S.Prabhakar, V.N.Banugopan, K.Annamalai, S.Jayaraj, "Optimization of Esters of Nerium Biodiesel in a Diesel Engine", Indian Journal of Science and Technology, 2011, 4(3), 170-172.

3. K.Suresh, G.Naidu, A.Venkata, "Performance and Emission Evaluation of a DI Diesel Engine Using Nerium Oil as Alternative Fuel", International Journal of Engineering Research and Technology, 2013, 2(9), 2510-2517.

4. I.J.Lalvani, M.Parthasarathy, D.Balasubramaninan, K.Annamalai, "Experimental Investigation on DI Diesel Engine with Renewable Biodiesel - Adelfa", National Conference on Green Engineering and Technologies for Sustainable Future 2014, Journal of Chemical and Pharmaceutical Sciences, 2014, Special Issue-4, 240-242.

5. C.B.John, M.Subramanian, "Study of Performance, Emission and Combustion Parameters of a Direct Injection Diesel Engine using Eucalyptus and Nerium Biodiesels as fuel", International Journal of Science, Engineering and Technology Research, 2014, 3(4), 692-698. 
6. N.Tyagi, A.Sharma, "Experimental Investigation of Neem Methyl Esters as Biodiesel on CI Engine", International Journal of Engineering and Applications, 2012, 2(4), 1673-1679.

7. Deokar, Harari, Sutar, Hodage, Patil, Kole, "Effect of Nozzle Hole Geometry on Compression Ignition Engine Fuelled with Thevetia Peruviana Biodiesel", International Journal of Innovative Research in Science, Engineering and Technology (IJIRSET), 2018, 7(12), 11861-11871.

8. Chavan, Sutar, Bhatkande, Gurav, Mulla, Deokar, Harari, "Experimental Studies on Production of Biodiesel from Thevetia Peruviana Feedstock", International Journal of Engineering and Management Research (IJEMR), 2018, 8(2), 46-49.

9. Harari, "Experimental Investigation on the Performance and Emission Characteristics of Compression Ignition Engine Fuelled with Various Blends of Water Melon Biodiesel", Integrated Research Advances (IRA), 2017, $4(1), 18-23$.

10. Harari, Ghadge, "Experimental Investigation on the Performance Characteristics of Compression Ignition Engine Fuelled with Various Blends of Calophyllum Inophyllum Biodiesel", International Research Journal of Engineering and Technology (IRJET), 2016, 3(8), 752-757.

11. C.Sayin, M.Gumus, M.Canakci, "Influence of injector hole number on the performance and emissions of a DI diesel engine fueled with biodiesel-diesel fuel blends", Applied Thermal Engineering 61 (2013) 121-128.

12. R.Sharma, R.R.Singh, S.K.Vishwakarma, "Experimental study of the effect of fuel injector nozzle holes on direct injection diesel engine", IOSR Journal of Mechanical and Civil Engineering, Volume-7, Issue-4, Pages 67-74, 2013.

13. L.P.Varghese, R.Saxena, R.R.Lal, "Analysis of the effect of nozzle hole diameter on CI engine performance using karanja oil-diesel blends", International Journal of Mechanical Engineering and Technology, Volume-4, Issue-4, Pages 79-88, 2013.

14. R.S.Kumar, "Experimental investigation of injectors nozzle hole on CI engine using jatropha oil as biofuel", International Journal of Scientific Research Engineering \& Technology, Volume-3, Issue-8, Pages 1209-1215, 2014.

15. R.L.Swamy, T.K.Chandrashekar, N.R.Banapurmath, P.Nashipudi, "Effect of injection timing, combustion chamber shapes and nozzle geometry on the diesel engine performance", Universal Journal of Petroleum Sciences 2 (2014), 74-95.

16. S.V.Khandal, N.R.Banapurmath, V.N.Gaitonde, R.S.Hosmath, "Effect of number of injector nozzle holes on the performance, emission and combustion characteristics of honge oil biodiesel (HOME) operated DI compression ignition engine", Journal of Petroleum and Environmental Biotechnology 2015, 6:3.

17. P.A.Harari, D.S.Akshatha, G.Manavendra, "Effect of Injection Pressure and Nozzle Hole Diameter on Combustion Parameters of CI Engine Fuelled with B20 Neem Blend", International Journal of Innovative Research in Science, Engineering and Technology, 2015, 4(5), 2857-2870.

18. P.A.Harari, G.Manavendra, "Experimental Investigation on the Combustion Parameters of B20 Neem Blend in CI Engine by Varying Injection Timing and Nozzle Hole Diameter", International Journal of Advanced Research and Innovative Ideas in Education, 2015, 1(4), 503-510.

19. P.A.Harari, J.S.Patil, "A Review on Effect of Nozzle Hole Geometry on the Performance, Combustion and Emission Parameters of CI Engine Fuelled with Diesel and Biodiesel", International Journal of Engineering and Management Research, 2016, 6(3), 39-48.

20. P.A.Harari, D.S.Akshatha, G.Manavendra, "Influence of Injection Pressure and Nozzle Hole Diameter on Performance of CI Engine Fuelled with B20 Neem Blend", National Conference on Trends and Innovations in Automation, Materials and Thermal Engineering held on 21 \& 22 May 2015 at Visvesvaraya Technological University, Mysuru. 